\title{
Robotic upper-limb neurorehabilitation in chronic stroke patients
}

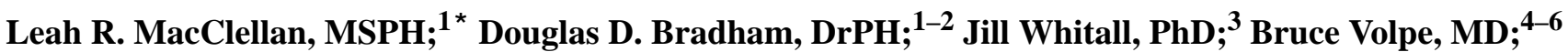 \\ P. David Wilson, PhD; ${ }^{1}$ Jill Ohlhoff, BA; ${ }^{3}$ Christine Meister, OTR; ${ }^{7}$ Neville Hogan, PhD; ${ }^{6,8}$ Hermano I. \\ Krebs, PhD; ${ }^{4,6}$ Christopher T. Bever Jr, MD $^{9-10}$ \\ ${ }^{1}$ Department of Epidemiology and Preventive Medicine, University of Maryland School of Medicine, Baltimore, MD; \\ ${ }^{2}$ Department of Veterans Affairs (VA), Health Services Research and Development Service, VA Medical Center \\ (VAMC), Baltimore, and Cooperative Studies Coordinating Center, VAMC, Perry Point, MD; ${ }^{3}$ Department of Physical \\ Therapy, University of Maryland School of Medicine, Baltimore, MD; ${ }^{4}$ Department of Neurology and Neurosciences, \\ Weill Medical College of Cornell University, New York, NY; ${ }^{5}$ Burke Medical Research Institute, White Plains, NY; \\ ${ }^{6}$ Department of Mechanical Engineering, Massachusetts Institute of Technology, Cambridge, MA; ${ }^{7}$ Department of \\ Physical and Occupational Therapy, VAMC, Baltimore MD; ${ }^{8}$ Brain and Cognitive Sciences, Massachusetts Institute of \\ Technology, Cambridge, MA; ${ }^{9}$ Department of Neurology, University of Maryland School of Medicine, Baltimore, MD; \\ ${ }^{10}$ Department of Neurology, VAMC, Baltimore, MD
}

\begin{abstract}
This pilot study tested the effectiveness of an intense, short-term upper-limb robotic therapy for improvement in motor outcomes among chronic stroke patients. We enrolled 30 subjects with upper-limb deficits due to stroke of at least 6 mo duration and with a Motor Power Assessment grade of 3 or less. Over 3 wk, 18 sessions of robot-assisted task-specific therapy were delivered with the use of a robotic exercise device that simulates a conventional therapy known as skateboard therapy. Primary outcome measures included reliable, validated impairment and disability measures of upper-limb motor function. Statistically significant improvements were observed for severely impaired participants when we compared baseline and posttreatment outcomes $(p<0.05)$. These results are important because they indicate that improvement is not limited to those with moderate impairments but is possible among severely impaired chronic stroke patients as well. Moderately and severely impaired patients in our study were able to tolerate a massed-practice therapy paradigm with intensive, frequent, and repetitive treatment. This information is useful in determining the optimal target population, intensity, and duration of robotic therapy and sample size for a planned larger trial.
\end{abstract}

Key words: elbow flexion, MIT-Manus, motor impairment, motor skills, neuromotor recovery, neurorehabilitation, outcome measures, rehabilitation, robot-assisted therapy, robotics, shoulder abduction, stroke, therapy.

\section{INTRODUCTION}

Stroke is a significant cause of disability among adults in the United States [1]. Although rehabilitation is available for acute stroke patients, few options exist for patients with moderate-to-severe chronic motor deficits due to stroke. This may be because of the majority of motor deficit recovery occurs within 6-months poststroke [2]. Research on task-specific massed-practice therapy (intensive therapy administered in a concentrated manner such as constraint-induced movement therapy [CIMT])

\footnotetext{
Abbreviations: CIMT $=$ constraint-induced movement therapy, FM = Fugl-Meyer, MIT = Massachusetts Institute of Technology, VA = Department of Veterans Affairs.

This material was based on work supported by grant V512(P)P-521-02 from the Rehabilitation Research and Development Service, Department of Veterans Affairs.

*Address all correspondence to Leah R. MacClellan, MSPH; Division of Healthcare Outcomes Research, Department of Epidemiology and Preventive Medicine, University of Maryland School of Medicine, 100 North Greene Street (lower level), Baltimore, MD 21201; 410-706-0066; fax: 410-7060098. Email: Imacclel@epi.umaryland.edu

DOI: 10.1682/JRRD.2004.06.0068
} 
indicates that motor deficits that remain beyond postacute rehabilitation may be in part due to learned nonuse and may be modifiable among subjects with mild-tomoderate upper-limb impairment [3-7]. Preliminary research also indicates that the intensity of training may be the most important component in CIMT for producing a treatment effect $[6,8-9]$. The generalizability of these results to chronic stroke patients with moderate-to-severe impairments is unclear.

To date, robot-assisted task-specific training has been administered with a less-intensive paradigm and has been associated with improved upper-limb motor scores for acute [10] and chronic stroke patients [11] with mild-tomoderate impairment and also for chronic [12] stroke patients in pilot studies with moderate-to-severe impairment. Our purpose was to obtain preliminary data for a controlled trial of the efficacy of upper-limb robotic therapy in patients with moderate-to-severe chronic deficits due to stroke by delivering a massed-practice intervention of half the duration and twice the intensity than has been previously reported with the MIT-Manus (Massachusetts Institute of Technology, Cambridge) [11-12].

\section{METHODS}

We have evaluated the efficacy of robot-assisted task-specific training among 30 volunteer subjects. Inclusion criteria were shoulder and elbow deficits due to stroke, stroke onset at least 6 months before enrollment, and a Motor Power Assessment grade of 3 or less for elbow flexion and shoulder abduction on the hemiplegic side [13]. Exclusion criteria were inability to give informed consent, contractures or orthopedic problems limiting the range of joint movement in the potential study arm, and visual loss such that the patient would not be able to see the test patterns on the monitor of the training apparatus.

Following their enrollment, we evaluated participants three times over 4 weeks to ensure stability of arm function. We used an average of the scores from all three evaluations to create baseline values and used repeatedmeasures analysis of variance to assess stability at baseline. Participants received 18 sessions of therapy delivered over 3 weeks: two sessions a day at 1 hour each, 3 days a week.

Therapy was delivered with InMotion2, a commercial version of the MIT-Manus, a robot developed at the
Massachusetts Institute of Technology, Cambridge, specifically for upper-limb neurorehabilitation [14]. Each training session consisted of goal-directed planar-reaching tasks that focused on the shoulder and elbow of the impaired arm. Subjects reached for eight targets equally spaced around a center target in a circular pattern with their involved arm using a novel performance-based algorithm to control the robot [15] while visual feedback on target location and robot handle motion was provided on a computer screen. The InMotion2 robot is highly backdrivable [16], which allows the patient to express movement. If the patient was unable to reach the target, the robot guided the patient's hand to the target. Subjects moved from the center target and back for each task in a clockwise direction; 672 specific arm movements were completed for each therapy session. A performance-based algorithm automatically adjusted the time and amount of assistance to reach each target, with each movement lasting between 1.5 and 4.5 s. Subjects rested during a 1-hour break between the first and second session each day.

Primary outcome measures included the upper-limb Motor Status Score [17], the Wolf Motor Function Test [18], the Motor Power Assessment [19], and the FuglMeyer (FM) Assessment upper-limb motor performance section [20]. An FM score of 15 or lower out of 66 defined impairment level as severe; otherwise, impairment level was defined as moderate. This was a clinically relevant division and was consistent with the level of joint action of patients; those having an FM score of 15 or below did not have any wrist or hand movement. Participants were evaluated for changes in motor function at the completion of the intervention and at 3 months postintervention. We used the Wilcoxon Signed Rank Test for paired data to evaluate differences in baseline and posttreatment outcomes and used SAS ${ }^{\circledR}$ (Statistical Analysis Software, Cary, North Carolina) to produce statistics [21].

The joint Department of Veterans Affairs and University of Maryland Institutional Review Board and the Massachusetts Institute of Technology Committee on the Use of Humans as Experimental Subjects approved this study, and each patient gave written informed consent before enrollment.

\section{RESULTS}

Of the 30 subjects who enrolled, 27 completed the intervention and 22 returned for the 3-month evaluation. Reasons for dropout before study completion included 
transportation difficulty (two subjects) and family emergency (one subject). Of the five subjects lost to followup, one had eye surgery, two lived out of the state and had transportation difficulty, and two were not available by telephone. No participant cited difficulty with the intervention or fatigue as a reason for dropout.

Of the 27 subjects who completed 3 weeks of treatment, 8 were classified as moderately impaired and 19 were severely impaired. The average FM score at baseline for the moderate group was 21.0, with a range from 16.0 to 29.3; average FM score for the severe group was 9.0, with a range from 4.0 to 13.7 .

Subject characteristics are shown in Table 1. Data are shown as mean \pm standard deviation. Twenty-one subjects were male and six were female and ages ranged from 42 to 79 years; the mean age was $54.6 \pm 11.3$ in the moderate group and $59.8 \pm 9.5$ in the severe group. All baseline measures were stable with the exception of an improvement of $3.63 \pm 5.05$ ( $p=0.002)$ on the Motor Power Assessment in the severe group from the first to the third baseline evaluation.

All motor function scores at baseline and posttreatment are shown in Table 2. Those subjects with severe impairments showed significant improvement in FM shoulder and elbow scores (increase of $1.5 \pm 1.8$ ) and Motor Power Assessment scores (increase of $4.3 \pm 6.4$ ).

The improvement on the Motor Power Assessment in the moderate group approached statistical significance with an increase of $3.5 \pm 5.1$. Positive trends were observed on the FM shoulder and elbow (increase of $1.1 \pm$ 1.8), and the Wolf Median Time (a reduction of $-3.9 \pm$ 10.7 ) in the moderate group; however, not none was statistically significant. Improvements on the Motor Status Score were not observed in either group. The Wolf Functional Ability measure indicated a small but significant

Table 1.

Mean \pm standard deviation for sex, age, and time since stroke for subjects with moderate and severe impairment levels.

\begin{tabular}{lcc}
\hline \multirow{2}{*}{ Characteristic } & \multicolumn{2}{c}{ Impairment Level } \\
\cline { 2 - 3 } & Moderate $(\boldsymbol{n}=\mathbf{8})$ & Severe $(\boldsymbol{n}=\mathbf{1 9})$ \\
\hline Male & $8(100 \%)$ & $13(68 \%)$ \\
Age & $54.6 \pm 11.3$ & $59.8 \pm 9.5$ \\
Time Since Stroke (mo) & $35.8 \pm 19.0$ & $53.9 \pm 56.9$ \\
Affected Arm & $3 \mathrm{R} / 5 \mathrm{~L}$ & $10 \mathrm{R} / 9 \mathrm{~L}$ \\
Lost to Follow-Up & $1(13 \%)$ & $4(21 \%)$ \\
\hline $\mathrm{R}=$ right, L = left. & \\
\hline \hline
\end{tabular}

improvement in the group with moderate impairment but not the group with severe impairment.

Motor function scores from posttreatment to 3-month follow-up are shown in Table 3. A statistically significant decrease in FM was observed among the moderate group; however, no significant changes were observed in the severe group. No adverse events associated with the intervention were reported during the study period.

\section{DISCUSSION}

Results of this evaluation of robot-assisted taskspecific therapy among chronic stroke patients with moderate-to-severe upper-limb deficits show promising trends toward improvement of motor function. Our findings indicate that robotic task-specific massed-practice therapy produced a significant and measurable benefit in the short term among severely impaired patients. Similar trends were observed among moderately impaired patients but were not significant. These findings are important because they indicate that improvement in motor ability is not limited to those with mild impairment but is possible among moderately to severely impaired chronic stroke patients and also that intensive, repetitive treatment can be tolerated by groups with moderate-tosevere upper-limb impairment.

Our study used a massed-practice intervention of half the duration and twice the intensity than has been previously reported with the MIT-Manus [11-12], and we observed smaller improvements. Our subjects were more severely impaired than those on whom Fasoli et al. [11] reported (as indicated by their reported average FM scores at baseline of $28.15 \pm 10.36$ ) but were comparable with subjects on whom Ferraro et al. [12] reported. For moderately and severely impaired patients, they reported significant improvements on the FM and Motor Power Assessment that remained robust at the 3-month followup. Furthermore, the occurrence of multiple strokes was an exclusion criterion in those studies [11-12] and not in our study, which corresponds approximately to half of our patients.

Our evaluations at 3 months posttreatment indicated no significant change from posttreatment evaluations, with the exception of the change observed on the FM in the moderately impaired group. Therefore, improvements observed immediately posttreatment did not appear to be lost at 3 months posttreatment in the severe group. 
Table 2.

Mean \pm standard deviation for motor function scores for moderately and severely impaired subjects at baseline and posttreatment.

\begin{tabular}{|c|c|c|c|c|c|c|c|c|}
\hline $\begin{array}{c}\text { Impairment } \\
\text { Level }\end{array}$ & $\begin{array}{c}\text { FM } \\
\text { Shoulder/ }^{*} \\
\text { Elbow }^{*}\end{array}$ & $\begin{array}{c}\text { FM Wrist/ } \\
\text { Hand }^{*}\end{array}$ & FM Total ${ }^{*}$ & $\begin{array}{c}\text { MSS } \\
\text { Shoulder/ } \\
\text { Elbow }^{\dagger}\end{array}$ & $\begin{array}{l}\text { MSS Wrist/ } \\
\text { Hand }^{\dagger}\end{array}$ & $\begin{array}{c}\text { Motor } \\
\text { Power } \\
\text { Assessment }^{\ddagger}\end{array}$ & $\begin{array}{l}\text { Wolf Median } \\
\text { Time (s) }\end{array}$ & $\begin{array}{c}\text { Wolf } \\
\text { Functional } \\
\text { Ability }^{\S}\end{array}$ \\
\hline \multicolumn{9}{|l|}{ Moderate $(n=8)$} \\
\hline Baseline Average & $21.0 \pm 5.3$ & $5.8 \pm 9.4$ & $26.9 \pm 14.2$ & $20.1 \pm 4.4$ & $6.3 \pm 9.5$ & $44.5 \pm 8.0$ & $39.1 \pm 52.3$ & $2.4 \pm 0.9$ \\
\hline Posttreatment & $22.1 \pm 5.3$ & $6.3 \pm 10.4$ & $28.4 \pm 15.1$ & $20.9 \pm 4.4$ & $6.7 \pm 10.9$ & $48.3 \pm 4.0$ & $35.2 \pm 52.6$ & $2.6 \pm 0.9$ \\
\hline Difference & $1.1 \pm 1.8$ & $0.4 \pm 1.8$ & $1.5 \pm 2.6$ & $0.7 \pm 1.5$ & $0.4 \pm 1.5$ & $3.5 \pm 5.1$ & $-3.9 \pm 10.7$ & $0.2 \pm 0.2$ \\
\hline \multicolumn{9}{|l|}{ Severe $(n=19)$} \\
\hline Baseline Average & $9.0 \pm 3.3$ & - & $9.0 \pm 3.3$ & $9.8 \pm 4.2$ & - & $27.5 \pm 13.2$ & $120 \pm 0.0$ & $1.3 \pm 0.2$ \\
\hline Posttreatment & $10.5 \pm 3.0$ & - & $10.5 \pm 3.0$ & $10.6 \pm 3.8$ & - & $31.7 \pm 11.9$ & $120 \pm 0.0$ & $1.2 \pm 0.1$ \\
\hline Difference & $\begin{array}{l}1.5 \pm 1.8 \\
\mathrm{~S}=70.5 \\
p=0.003\end{array}$ & - & $\begin{array}{l}1.5 \pm 1.8 \\
\mathrm{~S}=70.5 \\
p=0.003\end{array}$ & $\begin{array}{l}0.8 \pm 2.3 \\
S=36.0 \\
p=0.16\end{array}$ & - & $\begin{array}{l}4.3 \pm 6.4 \\
S=65.5 \\
p=0.006\end{array}$ & - & $\begin{array}{l}0.1 \pm 0.1 \\
\mathrm{~S}=13.0 \\
p=0.13\end{array}$ \\
\hline
\end{tabular}

Table 3.

Mean \pm standard deviation for motor function scores for moderately and severely impaired subjects at posttreatment and 3-month follow-up.

\begin{tabular}{|c|c|c|c|c|c|c|c|c|}
\hline $\begin{array}{c}\text { Impairment } \\
\text { Level }\end{array}$ & $\begin{array}{c}\text { FM } \\
\text { Shoulder/ } \\
\text { Elbow }^{*}\end{array}$ & $\begin{array}{l}\text { FM Wrist/ } \\
\text { Hand }^{*}\end{array}$ & FM Total ${ }^{*}$ & $\begin{array}{c}\text { MSS } \\
\text { Shoulder/ }^{\text {Elbow }^{\dagger}}\end{array}$ & $\begin{array}{c}\text { MSS Wrist/ } \\
\text { Hand }^{\dagger}\end{array}$ & $\begin{array}{c}\text { Motor } \\
\text { Power } \\
\text { Assessment }^{\ddagger}\end{array}$ & $\begin{array}{c}\text { Wolf Median } \\
\text { Time (s) }\end{array}$ & $\begin{array}{c}\text { Wolf } \\
\text { Functional } \\
\text { Ability }^{\S}\end{array}$ \\
\hline \multicolumn{9}{|l|}{ Moderate $(n=7)$} \\
\hline Follow-Up & $20.9 \pm 5.3$ & $7.0 \pm 11.0$ & $27.9 \pm 15.9$ & $20.9 \pm 4.6$ & $7.4 \pm 11.3$ & $49.6 \pm 7.0$ & $38.5 \pm 55.9$ & $2.6 \pm 1.1$ \\
\hline Difference & $\begin{array}{c}-2.3 \pm 2.1 \\
S=-2.5 \\
p=0.05\end{array}$ & $\begin{array}{c}-0.1 \pm 0.7 \\
\mathrm{~S}=-1.0 \\
p=1.0\end{array}$ & $\begin{array}{c}-2.4 \pm 2.6 \\
\mathrm{~S}=-12.0 \\
p=0.06\end{array}$ & $\begin{array}{c}-0.7 \pm 0.9 \\
S=-11.5 \\
p=0.06\end{array}$ & $\begin{array}{c}-0.2 \pm 0.9 \\
S=-2.0 \\
p=0.71\end{array}$ & $\begin{array}{l}0.7 \pm 5.7 \\
S=1.5 \\
p=0.86\end{array}$ & $\begin{array}{l}1.1 \pm 3.4 \\
S=-1.0 \\
p=0.88\end{array}$ & $\begin{array}{l}0.0 \pm 0.36 \\
\mathrm{~S}=0.5 \\
p=0.98\end{array}$ \\
\hline \multicolumn{9}{|l|}{ Severe $(n=15)$} \\
\hline Posttreatment & $10.9 \pm 3.0$ & - & $10.9 \pm 3.0$ & $11.1 \pm 3.5$ & - & $31.2 \pm 12.3$ & $120.0 \pm 0.0$ & $1.2 \pm 0.1$ \\
\hline Follow-Up & $10.1 \pm 2.6$ & - & $10.4 \pm 2.8$ & $11.5 \pm 3.4$ & 一 & $30.7 \pm 12.8$ & $120.0 \pm 0.0$ & $1.3 \pm 0.2$ \\
\hline Difference & $\begin{array}{c}-0.7 \pm 2.5 \\
\mathrm{~S}=-12.0 \\
p=0.38\end{array}$ & - & $\begin{array}{c}-0.7 \pm 2.5 \\
\mathrm{~S}=-12.0 \\
p=0.38\end{array}$ & $\begin{array}{l}0.4 \pm 2.1 \\
\mathrm{~S}=11.0 \\
p=0.51\end{array}$ & - & $\begin{array}{r}-0.5 \pm 5.2 \\
\mathrm{~S}=-3.5 \\
p=0.79\end{array}$ & - & $\begin{array}{c}0.1 \pm 0.1 \\
\mathrm{~S}=13.0 \\
p=0.08\end{array}$ \\
\hline
\end{tabular}

Our study showed greater evidence for improvement in motor function for severely impaired subjects than for moderately impaired subjects. The reason for this distinction is unclear; however, the main factor that distinguished the two groups was sample size. Similar outcomes were observed between groups on the FM and Motor Power Assessment but more than twice the number of subjects was in the severe group compared with the moderate group. 
Improvements measured with the Motor Status Score were not significant for moderately or severely impaired groups in these analyses. This finding is consistent with one other study in which no effect was observed on the Motor Status Score following robotic task-specific therapy in chronic stroke patients [12]. The Motor Status Score was developed as a sensitive indicator of change in motor function for acute stroke patients [17] but may need further validation as an appropriate measure for functional change in moderately to severely impaired chronic stroke patients.

Studies of repetitive task-specific interventions with a spaced-practice paradigm, such as repetitive bilateral arm training, and previous studies with the MIT-Manus have been associated with positive outcomes for chronic stroke patients with moderate [11,22] and severe [12] impairments. Previous studies of the MIT-Manus spaced treatments across 6 weeks compared with our intervention of 3 weeks. The observed improvements in these studies were substantially larger for moderately and severely impaired subjects than those observed in the present study [11-12]. The main factors that distinguished our study from these studies were the duration and intensity of the intervention.

Other massed-practice interventions, such as CIMT, have been successful among chronic stroke patients with moderate to mild impairment [3-4,6-7]. These studies suggest that task-specific treatment delivered in an intensive 2-week protocol could significantly improve motor function. Although our observed improvements were smaller than those from similar studies that used spaced practice, our findings indicate that patients were able to tolerate increased dose intensity. We did observe mild fatigue during the first 2 days of treatment and allowed for rest as needed. Beyond this, even the most severely impaired patients were able to tolerate the treatment intensity and repetitions in a session. We allowed for 1-hour rest breaks between treatment sessions; however, patients were usually ready to resume after only 30 minutes. Our experience should be interpreted carefully, but it is noteworthy that therapists may traditionally underestimate patient ability to tolerate intensive, frequent, or repetitive treatment.

This pilot study has several limitations. First, although we verified stability at baseline, we did not study a comparison group; therefore, we do not know how improvements observed in association with the study therapy compare with the absence of therapy. An effect of attention and motivation may be given to subjects by the supervising therapist. Second, our sample size was small; therefore, we are unclear as to whether the delivered treatment affected moderate and severe groups differently or whether we were unable to detect effects in the moderate group because of a smaller sample size. Also because of our small sample size in each group, we were unable to control for factors related to change in motor function other than level of severity.

\section{CONCLUSIONS}

Our intervention was half the duration and twice the intensity of previous studies of therapy delivered with the MIT-Manus [11-12]. Motor impairment scores demonstrated small but positive outcomes and treatment was well-received and tolerated by moderately and severely impaired subjects, which shows that robotic therapy may be useful for improving functional outcomes with a variety of time and intensity regimens. Researches should confirm these findings with a controlled trial and larger sample size to demonstrate the efficacy and cost-effectiveness of robot-assisted therapy in moderately and severely impaired chronic stroke patients.

\section{ACKNOWLEDGMENTS}

We would like to acknowledge Laura Safford, chief of occupational therapy at the VA Maryland Health Care System, and Susan E. Fasoli, Postdoctoral Associate in the Department of Mechanical Engineering at the Massachusetts Institute of Technology.

\section{REFERENCES}

1. Prevalence of disabilities and associated health. MMWR Morb Mortal Wkly Rep. 2001;50(7):120-25. Erratum in MMWR Morb Mortal Wkly Rep 2001;50(8):149.

2. Jorgensen HS, Nakayama H, Raaschou HO, Vive-Larsen J, Stoier M, Olsen TS. Outcome and time course of recovery in stroke. Part II: Time course of recovery. The Copenhagen Stroke Study. Arch Phys Med Rehabil. 1995;76(5):406-12.

3. Taub E, Miller NE, Novack TA, Cook EW 3rd, Fleming WC, Nepomuceno CS, Connell JS, Crago JE. Technique to improve chronic motor deficit after stroke. Arch Phys Med Rehabil. 1993;74(4):347-54. 
4. Van der Lee JH, Wagenaar RC, Lankhorst GJ, Vogelaar TW, Deville WL, Bouter LM. Forced use of the upper extremity in chronic stroke patients: Results from a single-blind randomized clinical trial. Stroke. 1999;30(11):2369-75.

5. Page SJ, Sisto S, Levine P, McGrath RE. Efficacy of modified constraint-induced movement therapy in chronic stroke: A single-blinded randomized controlled trial. Arch Phys Med Rehabil. 2004;85(1):14-18.

6. Taub E, Uswatte G, Pidikiti R. Constraint-induced movement therapy: A new family of techniques with broad application to physical rehabilitation-A clinical review. J Rehabil Res Dev. 1999;36(3):237-51.

7. Kunkel A, Kopp B, Muller G, Villringer K, Villringer A, Taub E, Flor H. Constraint-induced movement therapy for motor recovery in chronic stroke patients. Arch Phys Med Rehabil. 1999;80(6):624-28.

8. Taub E, Crago JE, Uswatte G. Constraint-induced movement therapy: A new approach to treatment in physical rehabilitation. Rehabil Psychol. 1998;43(2):152-70.

9. Taub E, Morris DM. Constraint-induced movement therapy to enhance recovery after stroke. Curr Atheroscler Rep. 2001;3(4):279-86.

10. Aisen ML, Krebs HI, Hogan N, McDowell F, Volpe BT. The effect of robot-assisted therapy and rehabilitative training on motor recovery following stroke. Arch Neurol. 1997;54(4): 443-46.

11. Fasoli SE, Krebs HI, Stein J, Frontera WR, Hogan N. Effects of robotic therapy on motor impairment and recovery in chronic stroke. Arch Phys Med Rehabil. 2003;84(4): 477-82.

12. Ferraro M, Palazzolo JJ, Krol J, Krebs HI, Hogan N, Volpe BT. Robot-aided sensorimotor arm training improves outcome in patients with chronic stroke. Neurology. 2003; 61(11):1604-7.

13. Kalra L, Crome P. The role of prognostic scores in targeting stroke rehabilitation in elderly patients. J Am Geriatr Soc. 1993;41(4):396-400.
14. Hogan N, Krebs HI, Sharon A, Charnnarong J, inventors; Massachusetts Institute of Technology, assignee. Interactive robotic therapist. United States patent US 5466213. 1995 Nov 15.

15. Krebs HI, Palazzolo JJ, Dipietro L, Ferraro M, Krol J, Rannekleiv K, Volpe BT, Hogan N. Rehabilitation robotics: Performance-based progressive robot-assisted therapy. Auton Robots. 2003;15(1):7-20.

16. Krebs HI, Hogan N, Aisen ML, Volpe BT. Robot-aided neurorehabilitation. IEEE Trans Rehabil Eng. 1998;6(1): 75-87.

17. Ferraro M, Demaio JH, Krol J, Trudell C, Rannekleiv K, Edelstein L, Christos P, Aisen ML, England J, Fasoli S, Krebs HI, Hogan N, Volpe BT. Assessing the motor status score: A scale for the evaluation of upper limb motor outcomes in patients after stroke. Neurorehabil Neural Repair. 2002;16(3):283-89.

18. Wolf SL, Catlin PA, Ellis M, Archer AL, Morgan B, Piacentino A. Assessing Wolf Motor Function Test as outcome measure for research in patients after stroke. Stroke. 2001; 32(7):1635-39.

19. Gregson JM, Leathley MJ, Moore AP, Smith TL, Sharma AK, Watkins CL. Reliability of measurements of muscle tone and muscle power in stroke patients. Age Ageing. 2000; 29(3):223-28.

20. Fugl-Meyer AR. Post-stroke hemiplegia assessment of physical properties. Scand J Rehabil Med Suppl. 1980;7: 85-93.

21. SAS Institute Inc. SAS ${ }^{\circledR}$ Procedures Guide, Version 8. Cary (NC): SAS Institute Inc; 1999. p. 1396.

22. Whitall J, McCombe Waller S, Silver KH, Macko RF. Repetitive bilateral arm training with rhythmic auditory cueing improves motor function in chronic hemiparetic stroke. Stroke. 2000;31(10):2390-95

Submitted for publication June 18, 2004. Accepted in revised form July 11, 2005. 